\title{
Imprisoned Sex Offenders' Chronic Denial and their Childhood Family Environment
}

\author{
Olivia Davids ${ }^{1}$, Marcel Londt ${ }^{*}, 1$ and Lizane Wilson ${ }^{2}$ \\ ${ }^{I}$ Department of Social Work, University of the Western Cape, Cape Town, South Africa \\ ${ }^{2}$ Centre for Child Youth and Family Studies, North-West University, Potchefstroom (Wellington) Campus, South Africa
}

\begin{abstract}
Statistics in South Africa shows that sex offences are among the crimes that invoke the most public concern as anywhere else in the world. The number of sentenced sex offenders is increasing and denial by the sex offender is regarded as a risk factor for re-offending. Sex offenders who chronically deny their offenses are not only perceived as having a greater likelihood of recidivism, but additional questions about their childhood experiences and their experiences in their families of origin are also raised. This study described the family environment of non-admitting sex offenders and explored whether any family characteristics influenced their denial of the sexual offence. Qualitative research was applied and ten (10) incarcerated, non-admitting sex offenders were purposively selected from a Correctional Facility in the Western Cape. Semi-structured interviews were conducted with the participants and Social Learning Theory was used as a lens to understand the dynamics. The findings of this study highlighted that most participants were raised in single-parent households with absent father figures, which had implications for their masculine identities and roles. These families were characterized by challenges such as domestic violence, substance abuse, unsatisfactory support and compromised parenting styles.
\end{abstract}

Keywords: Depersonalization, dynamic risk factor, family environment, masculinity, minimization, non-admitting sex offenders, Permissive parenting style, sex offenders.

\section{INTRODUCTION}

In South Africa, at least one in three women will be raped in her lifetime [1]. Crime statistics released in 2013 for the period April 2011 to March 2012 showed that there were 64,514 sexual crime cases reported to the South African Police Service (SAPS) [2]. A study conducted in 2010 showed that, in the Gauteng Province, more than $37 \%$ of men admitted to the rape of a woman and nearly $7 \%$ of the 487 men included in the survey admitted to participating in a gang rape [3]. This study is cited on the website of the Department of Correctional Services and the latest statistics on sex offenders within the system showed an increase in totals - the number of un-sentenced sexual offenders had risen to 6,949 and sentenced offenders to 18,058 [3]. This statistical evidence suggests that efforts to change the behaviour of sex offenders remain inadequate.

Sexual offences are among the crimes that invoke the most public concern [4]. Sex Offenders are defined as persons who have been convicted of a sexual offence in a criminal court [5]. Although progress has been made in the treatment of sexual offenders, gaining a greater understanding of what childhood adversities influence sexual deviant behaviour is still necessary for better treatment and prevention of sexual offending in society [6]. Many theories about the etiology of sexual offending postulate that negative

*Address correspondence to this author at the Department of Social Work, Private Bag x17 Bellville University of the Western Cape, South Africa; Tel: 27(21)959 2277; E-mail: mlondt@uwc.ac.za developmental events are precursors for the occurrence of sexual offending behaviour [6]. In the Integrated Theory of sexual offending it is proposed that poor socialization experiences, such as violent parenting, are responsible for the development of strong feelings of resentment and hostility, elements that are prevalent in sexual offending [6]. Another model, called the Causal Model of aggression against women, suggests that hostile childhood experiences, in terms of parental violence and child abuse, are associated with delinquency [7], which in turn leads to coerciveness against women [6].

It is the opinion of one research group that families of sex offenders are often characterized by frequent violence, family instability and disorganization [5]. They also posit that abusive sexual behaviour is strongly influenced by the family environment, as well as early sexual experiences [5]. Another research concurs that adverse family environments provide the breeding grounds for sexual offending [4]. This is in keeping with tenets of the Social Learning Theory which implies that we model the behaviour that we were exposed to as children, with our parents as the primary agents involved in our socialization process [8].

It is therefore asserted that family factors, such as inappropriate child rearing practices, parental conflict and family criminality, can predict offending behaviour [9]. Recent research into the history of many imprisoned sexual offenders exposed a family profile that included family violence, instability, alcoholism, housing problems and poverty.

Further evidence suggests that early traumatic experiences, such as childhood victimization, exposure to 
domestic violence, removal from the home, family disruption and parental loss due to death, incarceration and divorce are just some of the risk factors that contribute to the development of sexual offending [10]. It is argued that the experience of trauma and violence in childhood affects brain development-reduces the ability of children to form strong emotional relationships and develop empathy [11]. Many rapists have negative views of women; they endorse rape myths; they condone violence and display an over identification with the masculine role [12]. Exposure to violence in the home may desensitize the child to the effects of violence on victims, thus making them more likely to victimize others [13].

However, some sex offenders, in spite of being convicted, still deny committing the offence. It is suggested that denial is almost always characterized as an obstacle to treatment progress, whereas acceptance of responsibility is typically considered a treatment goal [14]. It is also asserted that offenders who deny responsibility and accountability of a committed offence are likely to be non-compliant with treatment tasks, resistant to accepting ownership of treatment goals and are more likely to fail completion of the treatment [14]. Research findings suggest that denial of the offence may be linked to family dynamics [15]. Through their denial, perpetrators might be protecting their families from stress and subsequent physical injury, or they might want to protect themselves from emotional rejection by family members. They might fear losing family members and friends if they admit to committing the sexual offence.

Deniers are often supported by their families in their denial [15]. This can be ascribed to the following reasons:

- Denial is seen as a coping mechanism used by both the offenders and their families to maintain a level of equilibrium;

- $\quad$ They could believe that denial protects them from any physical or emotional harm within the family and the community they live in;

- $\quad$ By being in denial, it protects the social and collective self-image of the family

It is therefore argued that denial and minimizations cause the continuation of offending once the first offence has been committed [14]. It is further argued that when an offender denies and minimizes his actions after the offence has taken place, it might be that the denial is grounded in distorted cognitions, and is evidence of pre-existing beliefs and attitudes [16].

This article is based on a study in which a qualitative approach was used to gain information that describes the family environment of non-admitting sex offenders. The study population was incarcerated, sentenced sex offenders who were accessed from a Correctional Services Correctional Facility in Cape Town, South Africa. The main objectives were to explore and describe the family environment and characteristics of non-admitting sex offenders and to determine how these participants viewed their own family environment. It must be noted that the scope of the study was specific to the incarcerated sex offenders and did not include the participation their families of origin.

\section{METHODOLOGY}

Qualitative research is one of the attempts to study human action from the perspective of the social beings themselves [17]. The strength of this approach is in its ability to provide in-depth information and descriptions about how people experience the given research issue. Qualitative research is concerned with understanding social and psychoanalytical phenomena from the perspectives of the people involved and interrogates the participants' experiences, beliefs and attitudes [18]. This study used the interpretivist design, which is based on the assumption that the meanings that participants give to the reality of their worlds are valued. It also means that their words shape their truths and not the way the researcher wishes to construct it [19].

In this study, non-admitting sex offenders provided insight into their family environment by sharing their childhood experiences. A name-list with the names of 15 sex offenders, who were found guilty of a sex offence but denied committing the offence, were provided to the researcher.

The following inclusion criteria were used to inform the purposive sampling:

- $\quad$ Participants had to be a current inmate in the prison;

- $\quad$ A conviction for a sexual offence;

- $\quad$ All participants should have been fully assessed by a social worker in Correctional Services, whose sole job description is the assessment of sex offenders at admission;

- $\quad$ Participants should have been assessed and identified as a non-admitting offender.

Age, race and gender were not considered and were excluded as selection criterion, since ethnicity of the participants did not appear to be significant to this study. An information session was held with all 15 sex offenders who met the inclusion criteria to introduce the researcher and explain the purpose of the study. Three of the participants immediately indicated that they did not want to participate in the study. Two of them were also disqualified because they admitted to committing the offence during the interviewing process. The details of the participants are as follows:

\begin{tabular}{|c|c|c|c|}
\hline Participant & Age & Sentence Length & Incarceration Period \\
\hline 1 & 31 & 18 years & 9 years 6 months \\
\hline 2 & 43 & 25 years (Life sentence) & 8 years \\
\hline 3 & 47 & 14 years & 8 years 6 months \\
\hline 4 & 45 & 15 years & 7 years 3 months \\
\hline 5 & 58 & 25 years (life) & 9 years \\
\hline 6 & 50 & 14 years & 7 years \\
\hline 7 & 36 & 15 years & 5 years 6 months \\
\hline 8 & 28 & 25 years (life) & 9 years \\
\hline 9 & 53 & 17 years & 11 years \\
\hline 10 & 52 & 25 years (life) & 11 years \\
\hline
\end{tabular}


Written permission was obtained from the Department of Corrections and the Ethics Committee of the University of the Western Cape. All participants were briefed regarding ethical obligations that apply to engaging in research activities. These included the aspects of confidentiality; anonymity; freedom to withdraw from participation without any negative consequences; access to trauma debriefing (if and when required) as well as informed and written consent for audio recording of the interviews.

The data for this study were collected through in-depth, face-to-face interviews with all ten participants. In-depth interviews are optimal for collecting data on the individuals' personal histories, perspectives and experiences [20]. An interview guide was developed by the researcher aimed at obtaining information on certain factors such as their family background-how they were raised, by whom, what was their relationship like with the care-giver.

After data collection, the data need to be analysed. Researchers state that qualitative data analysis involves several steps that need to be followed in the process of trying to understand and make sense of the information gathered. This study followed those steps. Firstly, the field notes were prepared and transcribed in order to be better familiarized with the data. The second step used theme identification from the data collected as it related to the research question. Step three involved the coding of the data. During the fourth step, the themes were elaborated by examining the data more closely. Identified themes were further grouped together to avoid duplication and repetition. The final step required reflecting on the understanding and interpretation of the data collected.

\section{RESULTS}

\section{Participants' Experience of Family Background}

During a child's early developmental years, the family is considered as primarily responsible for their care and development. The majority of the participants grew up in a family environment characterized by poverty, lack of basic resources, dysfunctional family life and emotional deprivation. The following refer to the salient findings that emerged from this study reporting on the experiences of the sex offender of their family environment.

Many of the participants made mention of the fact that one or both of their parents abused substances (either alcohol or drugs or both). Substance abuse within a family often leads to many social problems such as child neglect and maltreatment, poverty, domestic violence, financial problems, marital or relationship problems. For many of the participants the fact that their parent(s) abused substances meant that at some stage their parents failed to provide for their needs, be it emotional or material needs.

- $\quad$ "My father made use of alcohol. We were scared of him, because sometimes he broke stuff in the house. He fought with me a lot, and did not worry about the other children".

- "Only when he was under the influence of alcohol, then he would fight with me".
- "My mother drank a lot and that is why we children were removed from her care and placed in a children's home".

Many of the participants were exposed to domestic violence within the family home. In most instances they were subjected to violence by the male figure in the household. These results indicated that sexual offenders often reported a childhood history of physical abuse, suggesting that they learned violence in their family of origin and later introduced this violence into their own interpersonal relationships. The following quotations relate:

- "Yes. My stepfather beat my mother. I saw how he threw the flower pots at her".

- "Only when he was under the influence he would fight with me. He said he wanted to make a man out of me".

- $\quad$ "My father was never rude to our children, only with my mother, because when he came home he wanted money for alcohol".

\section{Participant's Relationship with Family Members}

Some of the participants were exposed to very harsh disciplinary methods within their family homes. At times, according to them, this contributed towards their 'rebellious nature'.

- $\quad$ "My stepfather imposed the discipline and whatever he said needed to be obeyed. He used to beat me a lot, maybe that was his way of imposing discipline".

- "My mother imposed the discipline when I did something wrong, but I can say that it was not sufficient, because I still did not listen to her".

- $\quad$ "My mother would handle the small stuff, but when we needed to be disciplined, by father would do it, and if you did not listen and do what father told you to do, he would give us a big hiding".

\section{Lack of Adequate Parental Supervision and Absent Fathers}

From the findings of the study, it was also evident that the parents neglected to provide sufficient guidance to and support for their children. Within the father-absent households, single-mothers and sometimes extended family members had the sole responsibility of guiding the children a task in which they were often unsuccessful due to their own problems, such as substance abuse. The following quotations relate:

- "My brother and his wife was unable to give me the motherly love I needed, so at the age of 11 years, I ran away from home, and ended up with the brokers in Cape Town".

Most of the participants grew up without knowing their biological fathers. In most cases the parents had already separated by the time the participant was born. Two of the participants said that they first made contact with their biological fathers when they were in their teenage years and adulthood, but many times they were unable to build and restore a proper father-son relationship. The following quotations relate: 
- "I don't know my father at all".

- $\quad$ "I was raised by my mother. By the time I was big my parents had already split up. My stepfather did not treat us well".

- "When I was 21 years old I first made contact with my biological father and it was only then that we stared to get to know one another".

- $\quad$ "I was raised by my mother. I was 2-years-old when my father went to prison. He got a sentence of 12 years".

-

"I grew up without a father in my life, and this caused me to go and look for a father figure outside the house and in all the wrong places".

One of the main themes highlighted in the study was the lack of a masculine identity, particularly a positive masculine identity. Many of the participants grew up without a fatherfigure, or knowledge of their biological fathers. From their responses it was evident that they felt deprived of the opportunity or benefit of a father-son relationship. Some of the participants had a father or a stepfather, but the relationship was seldom positive and healthy. For those who grew up with a father or stepfather, the father-son relationship was strained and often marked by physical and emotional abuse. The absence of the important positive male figure in their lives also meant that they lacked an example on which to model their own behaviour/character, or know what the role and responsibilities of a man within a household entailed.

\section{Lack of Stability in the Family Home}

Most of the participants came from an environment where there was no clear structure within the family home. Due to social problems such as domestic violence and substance abuse occurring in the home, children did not experience much stability. It would appear that this instability created chaotic conditions that caused unpredictable circumstances, contributing to intense adverse experiences for family members.

\section{Denial of the Offence}

Denial is a common characteristic of sex offenders. It is believed to be a defense mechanism that they use in order to protect themselves from harm, guilt and shame. In this study the findings suggest that denial often exists on a continuum that includes minimization of the impact of sexual assault on victims, blaming others for the offence and refusing to acknowledge the severity or chronicity of the sexual behaviour problem. During the data analysis process, all of the different phases of denial could be identified among the participants. Nine (9) of the ten (10) participants started off the interview process denying the offence. As the interviews, progressed some of them tried to minimize their offence, or they blamed someone else.

The results showed that 9 of the 10 participants, at one stage during the interview, said that they did not commit the offence they were accused of. As the interviews progressed, some of them would still deny, but would go through other stages of the denial process such as minimization, denial of certain aspects of the event. Ultimately, 5 of the 10 participants remained with their initial statement that they did not commit the offence.

\section{DISCUSSION}

\section{Family Structure and Parenting}

Most of the participants were raised in single-parent households. They were either raised by their mother or other family members. There were several risk factors present in the majority of the participants' accounts, which are characteristic of a dysfunctional family environment. However, simply being raised by a single mother does not automatically imply that the person will become a sex offender and deny responsibility for an offence. This finding suggested that there were other compounding negative factors that aggravated being raised by a single parent, usually a mother.

According to researchers, due to the lack of nurturance and guidance, the potential sex offender develops problems in social functioning, such as mistrust, hostility and insecure attachments, which in turn, are associated with social rejection, loneliness, negative peer associations and delinquent behavior [4].

The results in this study are supported by writers who assert that during childhood and adolescence, observations of how parents and significant others behave in intimate relationships provide an initial template for learning of behavioural alternatives [8]. It is agreed that early childhood experiences, especially those that occur within the context of the family, take a primary role over all other influences and are the most important determinant of future behaviour [15].

A South African research study also states that children tend to turn to criminal behaviour more easily when families fail to provide for their emotional needs [21]. This study further posits that research on youth and adult offenders have shown that most offenders suffer adverse childhood experiences in comparison to non-offenders [21]. Children who have experienced emotional deprivation, family violence, the lack of much needed support from their parents and negative child-rearing patterns, feel an emotional emptiness that directly influences their actions and their behaviour [21].

\section{Absent Fathers \& Lack of Masculine Identity}

Studies on family structure and children's outcomes consistently find that children raised in two-parent families do better than children raised in single-parent families on measures of educational achievement and adjustment [22]. They posit that children in disadvantaged populations are more likely to grow up in father-absent households, as marriage rates are lower and fertility is higher [23]. In society, men usually hold a higher social status than women because, in most cases, they are better paid and have better access to certain resources.

Children growing up without their fathers are more likely to experience emotional disturbances [24]. Male children seem to be affected more by father-absence because it affects their social competence and they are more likely to engage in 
stereotypical masculine behaviour that includes aggression [25]. Researchers reiterate that boys growing up in absentfather households are more likely to display hyper-masculine behaviour, including aggression [24]. Others caution that many rapists have negative views of women, they often endorse rape myths, they condone violence and display an over identification with the masculine role [12].

The majority of the participants confirmed that they never knew their biological fathers. Their parents were either unmarried or their fathers had already left by the time they were born. Most of them therefore, grew up without ever knowing their biological fathers during their younger years. Some of the participants only reunited with their biological fathers, in their adulthood. In many instances, they were denied opportunities to develop a father-son relationship. Some of the participants were raised by a step-father, but mainly described this relationship with the stepfather as hostile.

Many of the participants grew up without a positive male role model in their lives. For those who had a father or a stepfather in the house, the experience was mostly negative. During the interviews, it was apparent that most of the participants could not give a clear description of what role a man should play in the household. Many of them said that they had never had the experience of being in a stable relationship with a woman and children. They struggled to identify what the responsibilities of a man within a household entailed. It was evident that many of them had a distorted view of what exactly the individual roles and responsibilities of a man and a woman within a household are.

\section{Substance Abuse by One or Both Parents}

Most of the participants mentioned that either one or both of their parents abused alcohol or drugs. Two of the participants mentioned that their mothers abused alcohol excessively. This affected their ability to deliver proper care resulting in neglect of their children and their needs. Some other participants also felt that their most traumatic experiences as a child occurred while their parents were intoxicated. For some it was a reminder of the fear of having to flee their home or the abuse that they had to endure.

Another concern was that many of the participants also admitted to using/abusing alcohol/drugs and physically abusing their own partners while under the influence of substances. This theme is supported by the principles of the Social Learning Theory which state that most behaviour is learned through the modeling of others' behaviour. When applied to the context of the family Social Learning Theory states that we model the behaviour that we were exposed to as children [8].

\section{Domestic Violence Within the Household}

Many of the respondents said that they had witnessed many incidences of domestic violence between their parents and family members while growing up. In most instances, it was the father or stepfather who physically abused the mother while one, or both, were intoxicated. This study confirmed what the Social Learning Theory explains how behaviour is mimicked and repeated, especially with domestic violence [8]. Through their witnessing of these events, the participants learned the behaviour and eventually replicated domestic violence within their own adult relationships.

Families of violent offenders and sexual offenders have consistently shown high levels of negative affect and low levels of positive affect, which suggest that these families have low levels of bonding [26]. This Australian study showed that higher delinquency scores were associated with low parental care and bonding [26]. Studies on the families of adolescent sexual abusers have shown difficulties within the family constellation, including family relations that were characterized by rigidity and low cohesion, domestic violence between parents, difficult relationships among family members, broken homes, absence of parents in the lives of the youth and a lack of both nurturance and supervision [27]. In addition, research also posit that many adolescent sexual abusers have witnessed criminality, substance abuse and domestic violence in their homes [20].

\section{CONCLUSION}

The basic premise of this article was to explore and describe the family environment of a small sample of ten incarcerated sex offenders who have chronically denied their sexual offenses. The findings of this study showed that their families of origin were characterized by challenges such as unsatisfactory family structure and parenting, the absence of a father figure and the consequent lack of a positive masculine identity, substance abuse challenges as well as domestic violence.

The outcome of this study strongly suggests that those sex offenders who chronically deny and refuse to accept responsibility for their sexual violence may be mimicking the challenges that are embedded in their families of origin. However, it should also be noted that in the South African correctional facilities, sexual offenders are not separated from the general prison population. Sex offenders may be obligated to participate in specific programs prior to release, but chronic deniers are simply offered awareness raising or educational inputs rather than psycho-educational programs. The influence of prison gang activity and the prison gang industry cannot be ignored as an influencing factor that may impact on chronic denial. Admittedly, the sample size in this study is small, but the findings do alert one of the important issues that need to be addressed in South Africa, where the incidence of sexual violence remains critical.

Denial is a common characteristic with most sex offenders and a defense mechanism that is used in order to protect themselves from harm, guilt and shame. Refusing to accept the severity or chronicity of the problem may be more of a mechanism to protect themselves from a myriad of experienced problems within the family context [28].

The implications of these findings strongly advocate that intervention, prevention and remedies with sexual offenders must include supportive programmes for families. The findings of this study also clearly show that interventions with sexual offenders can never be delivered in a vacuum and must include strategies that address those factors that can develop capacity in families. Denial often exists on a 
continuum that includes minimization of the impact of sexual assault on victims, blaming others for the offence and refusing to acknowledge the severity or chronicity of the sexual behaviour problem. However, it is interesting that the denial of the participants is in this study also appears to include a denial of their own supposed victimization. None of the participants responded to the question on their own possible sexual victimization during childhood. Therefore, it may be a possibility that chronic deniers of sexual offences may also be in denial of their own sexual victimization in childhood and that this link may require further exploration in future research.

\section{CONFLICT OF INTEREST}

The authors confirm that this article content has no conflict of interest.

\section{ACKNOWLEDGEMENTS}

Declared none.

\section{REFERENCES}

[1] Moffett H. These women, they force us to rape them: Rape as narrative of social control in post-apartheid South Africa. J South Afr Stud 2006; 32(1): 129-44

[2] Crime Report, South African Police Services [Online] 2011/2012, [Accessed January, 2013]. Available from: http://www.issafrica. org.

[3] Department of Correctional Services [Online] 2012 Feb 10, [Accessed November, 2013]. Available from: www.dcs.gov.za.

[4] Hanson RK, Morton-Bourgon KE. The characteristics of persistent sexual offenders: A meta-analysis of recidivism studies. J Consult Clin Psychol 2005; 73(6): 1154-63.

[5] Barberee HE, Marshall WL. An introduction to the juvenile sex offender: terms, concepts and definitions. In: The Juvenile Sex Offender, UK: Guilford Press 2008; pp. 1-10.

[6] Lee JKP, Jackson HJ, Pattison P, Ward T. Developmental risk factors for sexual offending. Child Abuse Neglect 2002; 26: 73-92.

[7] Malamuth N, Sockloskie R, Koss M, Tanaka J. Characteristics of aggressors against women: Testing a model using a national sample of college students. J Consult Clin Psychol 1991; 59(5): 670-81.

[8] Mihalic SW, Elliot D. A social learning theory of marital violence. J Fam Violence 1997; 12(1): 21-47.

[9] Haas H, Farrington DP, Killias M, Sattar G. The impact of different family configurations on delinquency. Br J Criminol 2004; 44(4): $520-32$.
[10] Maniglio R. The role of childhood trauma, psychological problems and coping in the development of deviant sexual fantasies in sexual offenders. Clin Psychol Rev 2011; 31: 748-56.

[11] Seedat M, Van Niekerk A, Jewkes R, Suffla S, Ratele K. Violence and injuries in South Africa: prioritizing an agenda for prevention. Lancet 2009; 374 (9694): 1011-22.

[12] Robertiello G, Terry KJ. Can we profile sex offenders? A review of sex offender typologies. Aggress Violent Behav 2007; 12: 508-18.

[13] Caputo AA, Frick PJ, Brodsky SL. Family violence and juvenile sexual offending: The potential mediating role of psychopathic traits and negative attitudes toward women. Consult Crim Justice Behav 1999; 26(3): 338-56.

[14] Schneider SL, Wright RC. Understanding denial in sexual offenders: a preview of cognitive and motivational processes to avoid responsibility. Trauma Violence Abuse 2004; 5(1): 3-20.

[15] Cooper S. Understanding, treating and managing sex offenders who deny their offence. J Sex Aggress 2005; 11(1): 85-94.

[16] Ware J, Mann R. How should acceptance of responsibility be addressed in sexual offending treatment programs? Aggress Violent Behav 2012; 17: 279-88.

[17] Babbie E, Mouton J. The practice of social research. Cape Town, South Africa: Wadsworth Publishing Company 2001.

[18] Wellman C, Kruger F, Mitchell B. Research Methodology. Southern Africa: Oxford University Press 2005.

[19] De Vos AS, Strydom H, Fouché CB, Delport CSL. Research at Grass Roots. Pretoria, South Africa: Van Schaik Publishers 2011.

[20] Mack N, Woodsong C, MacQueen K, Guest G, Namey E. Qualitative research methods: a data collector's field guide. USA: Family Health International 2005.

[21] Mandisa T. Home and family circumstances of young offenders: An examination of social workers views. Br J Commun Justice 2007; 5(3): 63-80.

[22] Jaffee S, Moffitt T, Caspi A, Taylor A. Life with (or without) father: The benefits of living with two biological parents depend on the fathers' antisocial behaviour. Child Develop 2003; 74(1): 10926.

[23] Harper C, McLanahan S. Father absence and youth incarceration. J Res Adolesc 2004; 14(3): 369-97.

[24] Holborn L, Eddy G. First steps to healing the South African family. Johannesburg, South Africa: South African Institute of Race Relations 2011.

[25] Richter L. The importance of fathering for children. In: Baba: Men and fatherhood in South Africa. Cape Town, South Africa: HSRC Press 2006; pp. 53-72.

[26] Goldstein M, Heaven PCL. Perceptions of the family, delinquency and emotional adjustment among youth. Person Individ Differ 2000; 29:1169-78.

[27] Burton D, Meezan W. Revisiting recent research on Social Learning Theory as an etiological proposition for sexually abusive male adolescents. J Evid-Based Soc Work 2004; 1(1): 41-80.

[28] Levenson JS, Macgowan MJ. Engagement, denial and treatment progress among sex offenders in group therapy. Sex Abuse 2004; 16(1): 49-63. 